\title{
Acute Respiratory Infection and Influenza Surveillance Form
}

\author{
Criteria for patient selection and testing \\ symptom onset within 4 days \\ - $\quad$ any two of the following \\ o rhinorrhea \\ o nasal congestion \\ 0 sneezing \\ o sore throat \\ o cough \\ o fever
}

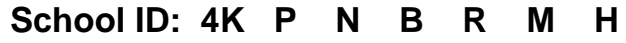

Participant ID:

Age:

Date of Collection:

Days between illness onset and today's visit: days

Exposure to a similar illness 1-3 days prior to ARI onset? Yes No

Likely Source: $\quad$ Classmate Friend Family Member (Adult / Sibling) Other:

Household Member (circle if living in household, check box if ill with similar ARI):

$\begin{array}{clll}\text { Grandmother } \square & \text { Grandfather } \square & \text { Mother (Female Guardian) } \square & \text { Father (Male Guardian) } \square \\ \text { O/Y Sibling \#1 } \square & \text { O/Y Sibling \#2 } \square & \text { O/Y Sibling \#3 } \square & \text { Other Adult: } \\ \text { O/Y Sibling \#4 } \square & \text { O/Y Sibling \#5 } \square & \text { O/Y Sibling \#6 } \square & \text { Other Child:_ } \\ \text { Recent Travel? } & \text { Yes } & \text { No } & \text { Recent Exposure to Farm Animals? }\end{array}$

Race: White Am Indian or Ak Native Asian Black Native Hawaiian or Other Pacific Islander

Ethnicity: Hispanic Non-Hispanic

Measured Temperature __ $\quad{ }^{\circ} \mathrm{F} \quad$ Antipyretic use within the last 6 hours? $\quad$ Yes No

Symptoms (circle all that are present):

$\begin{array}{llllll}\text { Fever } & \text { Chills } & \text { Cough } & \text { Wheezing } & \text { Runny Nose } & \text { Sore Throat } \\ \text { Malaise } & \text { Myalgia } & \text { Arthralgia } & \text { Nasal Congestion } & \text { Headache } & \text { Ear Pain } \\ \text { Anorexia } & \text { Vomiting } & \text { Abdominal Pain } & \text { Diarrhea } & \text { Conjunctivitis } & \text { Other: }\end{array}$

Influenza antiviral treatment for this illness prior to this visit?

Yes No

Seasonal influenza vaccine prior to this illness?

Yes No

Visit to health care provider for this illness prior to home visit?

Yes (specify when

Visit to health care provider planned in next few days?

Yes (specify when

- - - - - - - - - ITEMS BELOW THIS LINE FOR LABORATORY ONLY - - -

Sofia Result: $\quad \square$ flu A $\quad \square$ flu B $\quad \square$ both $\square$ negative $\square$ invalid

Sample Code:

$$
\frac{\text { ORCHARDS }}{\text { site }}-\frac{}{\text { week }}{ }^{-} \frac{\text { staff }}{}^{-} \frac{}{\text { sample }}
$$

Public reporting burden of this collection of information is estimated to average 30 minutes per response, including the time for reviewing instructions and completing and reviewing the collection of information. An agency may not conduct or sponsor this survey, and a person is not required to respond to a collection of information, unless it displays a currently valid OMB Control Number. Send comments regarding this burden estimate or any other aspect of this collection of information, including suggestions for reducing this burden to CDC/ATSDR Reports Clearance Officer, 1600 Clifton Road NE, MS D-74, Atlanta, Georgia 30333; ATTN: PRA 0920-1039. 